\title{
AVALIAÇÃO DO EFEITO DA UMIDADE NAS PROPRIEDADES DE ESCOAMENTO DE DIFERENTES TIPOS DE AÇÚCAR
}

\author{
P. M. SILVA \& R. CONDOTTA
}

\author{
Centro Universitário da FEI, Departamento de Engenharia Química \\ E-mail para contato: rcondotta@fei.edu.br
}

\begin{abstract}
RESUMO - O açúcar é uma importante matéria prima na indústria de bebidas, doces, lácteos e também em produtos de panificação. O açúcar é atualmente comercializado de várias formas, dentre as quais citam-se: cristal, mascavo, refinado, confeiteiro, demerara, orgânico, VHP ("very high polarization"), sendo este destinado exclusivamente a exportação. Durante o manuseio doméstico de açúcar é comum observar a formação de aglomerados ou mesmo empedramento total de uma embalagem de açúcar, entretanto esta quantidade é ínfima quando comparada com a capacidade industrial onde estes mesmos problemas nesta escala são preocupantes. Tais fenômenos podem causar dificuldades de transporte e manuseio nas operações de descarga, empacotamento e armazenamento, resultando em prejuízos econômicos e eventual perda de qualidade do produto. A origem deste problema está ligada ao surgimento de forças de resistência ao escoamento (forças de coesão entre as partículas) como consequência das diferentes propriedades físicas do próprio material, tais como diferenças na granulometria, formato e rugosidade de superfície das partículas, ou mesmo devido a variações nas condições de processamento ou armazenamento do produto. O objetivo desse trabalho foi avaliar a escoabilidade de 4 tipos de açúcar (cristal, mascavo, refinado e confeiteiro) com base em medidas experimentais e análises de índices de escoabilidade e em como essas propriedades podem ser afetadas pela incorporação de umidade.
\end{abstract}

\section{INTRODUÇÃO}

Indústrias que atuam nos setores de manufaturados, como alimentício e farmacêutico, semimanufaturados, como ferro e aços, ou até mesmo as agroindústrias, utilizam a tecnologia de pós a fim de facilitar o manuseio, processamento e transporte de seus produtos. Tanto os materiais pulverulentos quanto os grãos são comumente chamados de "bulk solids".

Entretanto em inúmeras etapas de processo ou armazenamento desses sólidos particulados, são encontradas dificuldades que demandam tempo e custo para a indústria, sendo estas, principalmente relacionadas ao escoamento do material entre operações unitárias da linha de processo. O escoamento de uma partícula, ou seja, o movimento dela sobre outra partícula está relacionado a uma deformação submetida ao material como resultado de uma tensão cisalhamento. Esta tensão de cisalhamento seria uma dada força que se sobressai às forças de resistência ao escoamento. No estudo de sólidos, as forças gravitacionais, forças de atrito entre as partículas, forças intermoleculares (coesão e atração entre as partículas), e forças de adesão 
entre as partículas e a parede do material que as contem, são consideradas para a definição da força de resistência ao escoamento (Juliano; Barbosa-Cánovas, 2010). O resultado obtido da análise dessas forças em um sistema pode indicar o quão apto o material está para o escoamento, ou seja, se escoa com facilidade, com dificuldade ou ocorre ausência de escoamento. A intensidade dessas forças depende de inúmeras características das partículas, como por exemplo, o tamanho, pois quanto menor a partícula, maior é a área de superfície de contato para interações das forças de coesão (Fitzpatrick et al., 2004).

Para materiais higroscópicos ou com certo teor de umidade, o aumento ou presença de água na sua composição pode afetar significativamente as propriedades de escoamento, pois a água é adsorvida na superfície da partícula, e qualquer alteração na superfície influencia na intensidade de coesão (Fitzpatrick et al., 2004).

A consolidação do material durante o tempo de armazenamento, muitas vezes também é referido como grande problema ao manusear pós, por formar caking, que é o fenômeno de aglomeração de sólidos particulados, geralmente causado pela umidificação da superfície da partícula que causa a sua plastificação e por vezes a dissolução. Isto acontece especialmente para as superfícies amorfas, ou seja, que não possuem forma geométrica específica. Então, posterior ao armazenamento, é necessário um processo de moagem para transformar os bolos formados em partículas individuais ou aglomerados menores.

Entretanto em alguns casos, um processo de moagem não é eficaz porque a estrutura das partículas pode ser destruída, fazendo-se necessárias outras técnicas mais sofisticadas de separação das partículas, ou até, manualmente. Além disso, a qualidade dos produtos embalados em pó é negativamente afetada pelo caking durante o armazenamento ou transporte. Para reduzir os custos de processamento, pós-tratamento e aumentar a qualidade dos produtos finais este fenômeno deve ser evitado (Hartmann e Palzer, 2011).

\subsection{Açúcar}

É sabido que o açúcar é um material comumente utilizado por indústrias do setor alimentício como matéria-prima básica de produtos como: bebidas, produtos de panificação, confeitos, snacks, etc. Após processado, o açúcar pode ser comercializado ou submetido a mais etapas de processamento, dependendo das características e finalidade do produto que se deseja obter. Neste sentido, traz-se o fato de que a menor parcela do açúcar brasileiro é destinada ao mercado interno (37\%), distribuído para as indústrias de atacado e varejo. No caso do mercado externo, o açúcar é exportado tipo Very Hight Polarization (VHP), que é utilizado como insumo no processo de refinação. O mercado de açúcar atende ao comércio atacadista que, por conseguinte, distribuirá o produto para o comércio varejista e indústria de alimentos que, por fim, destinará o produto ao consumidor final (Machado, 2012). Dentre os diferentes tipos de açúcares comerciais, temos alguns, como o refinado (muito utilizado como adoçante de mesa pelos brasileiros), cristal, mascavo, confeiteiro, impalpável, entre outros, são processados de acordo com sua finalidade.

\section{METODOLOGIA E RESULTADOS}

Para cumprir o objetivo deste estudo, foram realizados alguns testes padrões a fim de estudar os fatores que influenciam o escoamento de diferentes açúcares: o Açúcar VHP 
fornecido pela Usina São Martinho, os açúcares Refinado e Confeiteiro comerciais, da marca comercial União, e o Cristal da marca Colombo.

As amostras foram subdivididas em dois grupos: Grupo A - referente aos açucares secos, ou seja, com umidade normalizada para o consumo ou aplicação; Grupo B - referente aos açúcares umidificados em solução aquosa saturada de cloreto de sódio para controle da porcentagem de umidade, por um período de 15 dias. Todas as amostras foram submetidas à mesma sequência de testes à temperatura ambiente de $25^{\circ} \mathrm{C}$.

\subsection{Granulometria e Conteúdo de Umidade}

A presença de água em meio particulado intensifica forças de coesão devido à intensidade das pontes líquidas, as quais também são função da granulometria do açúcar. Para a determinação do tamanho das partículas dos açucares testados, utilizou-se o analisador por difração à laser modelo Bluewave da marca MicroTrac. Já a conteúdo de umidade foi determinada com auxílio do analisador de umidade por infravermelho IV-2000 da marca Gehaka. Os valores obtidos são apresentados na Tabela 1.

Tabela 1 - Tamanho e conteúdo de umidade para as amostras secas e úmidas

\begin{tabular}{|c|c|c|c|c|}
\hline Material Seco & Açúcar Cristal & Açúcar Refinado & Açúcar Confeiteiro & Açúcar VHP \\
\hline $\mathrm{d}_{[4,3]}-$ vol. $(\mu \mathrm{m})$ & 657 & 334 & 161 & 740 \\
\hline Umidade $(\%)$ & 0,20 & 0,20 & 0,70 & 0,20 \\
\hline Material Úmido & Açúcar Cristal & Açúcar Refinado & Açúcar Confeiteiro & Açúcar VHP \\
\hline Umidade $(\%)$ & 0,40 & 0,90 & 1,8 & 0,30 \\
\hline
\end{tabular}

\subsection{Densidades bulk aerada e compactada}

Diferente da densidade ou massa específica real, que caracteriza a partícula, a densidade bulk representa a densidade de um conjunto de partículas, ou seja, um leito constituído por um conjunto de partículas. Assim, o volume ocupado por uma determinada massa de leito irá depender da maneira como as partículas se acomodam e isso estará relacionado com a condição na qual o leito foi formado (vibrações, segregação, etc.), ao atrito entre as partículas (que permitem o deslizamento de umas sobre as outras), às forças internas de coesão (que permitem inferir sobre a tendência na formação de aglomerados), o formato das partículas e outros fatores (Peleg, 1977). O teor de umidade do material pode alterar a densidade bulk uma vez que se intensificam as forças de coesão devido a presença de pontes líquidas e diminui a porosidade desses materiais (Scicolone et al., 2015).

Neste trabalho, a densidade bulk aerada e compactada foram obtidas através da análise experimental com o auxílio do equipamento Atuo Tap, modelo Tap-2S, na marca Logan Instruments, segundo a norma USP-I. O método consiste em colocar certa massa de amostra em um recipiente volumétrico (proveta) de massa conhecida, e submeter o sistema (material + proveta) à um número de batidas programado pelo operador. $\mathrm{O}$ volume da proveta padronizado para este estudo foi de $80 \mathrm{~mL}$, e a partir dele e da massa de material, foi possível obter a densidade aerada, e o volume obtido após um total de 2000 batidas em relação a massa do 
material, calculou-se a densidade bulk, conforme Equação 1 e 2, e os resultados são apresentados na Tabela 2.

$\rho_{\text {bulk aerada }}=\frac{m_{\text {leito aerado }}}{V_{\text {leito aerado }}}$

$\rho_{\text {bulk compactada }}=\frac{m_{\text {leito compactado }}}{V_{\text {leito compactado }}}$

A alteração de densidade devido à compactação pode ser um índice da presença de forças de atração e de fricção e é comumente utilizada como um indicativo da fluidez de materiais particulados, denominada Índice de Hausner, através da Equação 3, e classificados de acordo com a literatura do método, cuja classificação também se encontra na Tabela 2.

$H r=\frac{\rho_{\text {bulk compactada }}}{\rho_{\text {bulk aerada }}}$

Tabela 2 - Densidades bulk (aerada) e compactada, para as amostras secas e úmidas

\begin{tabular}{|c|c|c|c|c|}
\hline Material Seco & Açúcar Cristal & Açúcar Refinado & Açúcar Confeiteiro & Açúcar VHP \\
\hline$\rho \_$compactada $\left(\mathrm{g} / \mathrm{cm}^{3}\right)$ & 0,9970 & 0,8334 & 0,6789 & 0,9569 \\
\hline$\rho \_$aerada $\left(\mathrm{g} / \mathrm{cm}^{3}\right)$ & 0,9378 & 0,7188 & 0,5984 & 0,8971 \\
\hline $\begin{array}{c}\text { Classificação do } \\
\text { Fluxo }\end{array}$ & Excelente & Bom & Bom & Excelente \\
\hline Material Úmido & Açúcar Cristal & Açúcar Refinado & Açúcar Confeiteiro & Açúcar VHP \\
\hline$\rho \_$compactada $\left(\mathrm{g} / \mathrm{cm}^{3}\right)$ & 0,9794 & 0,7354 & 0,6437 & 0,9012 \\
\hline$\rho \_$aerada $\left(\mathrm{g} / \mathrm{cm}^{3}\right)$ & 0,9355 & 0,6233 & 0,5311 & 0,83434 \\
\hline $\begin{array}{c}\text { Classificação do } \\
\text { Fluxo }\end{array}$ & Excelente & Bom & Razoável & Excelente \\
\hline
\end{tabular}

Observa-se que apesar da diferença de umidade, de acordo com o índice de Hausner, não houve alteração da classificação do fluxo, exceto para o Açúcar Confeiteiro que mudou de "Bom" para "Razoável", por ser o que mais agregou umidade, aumentou a aglomeração de partículas no leito, portanto maior influência das forças interparticulares, sendo necessária uma energia maior para que ocorra o escoamento.

\subsection{Reômetro de Pó FT-4}

O reômetro de pó FT4 da marca Freeman usa o princípio da mensuração da energia necessária para garantir o movimento constante de uma lâmina num trajeto helicoidal através de um leito de pó. Uma ampla gama de padrões de fluxo e taxas de fluxo pode ser alcançada dependendo da direção e velocidade de movimento. Todas as forças que atuam sobre a pá, incluindo a força axial e a força de rotação ou o binário, são medidas. Estes dados são utilizados para calcular o trabalho realizado no deslocamento do pó - a base da avaliação da fluidez. Em contraste com os métodos tradicionais que geram um único número de resultados, esta abordagem reconhece a natureza complexa dos pós e a necessidade de avaliar as propriedades de fluxo em relação às muitas variáveis-chave, incluindo a taxa de fluxo, aeração, consolidação e teor de umidade. 
Função de Fluxo (FF): A função de fluxo é determinada através do teste de cisalhamento no Reômetro de pós FT-4, as quais foram realizadas neste trabalho sob tensões de consolidação de 3, 6, 9 e $15 \mathrm{kPa}$. Após a etapa de consolidação, inicia-se a etapa de cisalhamento propriamente dita sob tensões inferiores a de consolidação. A medida que o leito resiste à rotação da cabeça de cisalhamento, a tensão de cisalhamento aumenta até o leito falhar ou romper, situação em que é observada a máxima tensão de cisalhamento. O conjunto destas tensões de cisalhamento permite estimar ponto de ruptura ou o "yeld loci" para a dada tensão de consolidação da amostra; e o conjunto de "yield loci" permite obter todos os parâmetros necessários para a obtenção da função de fluxo (FF) de um material

Na Figura 1 estão delimitas as regiões de escoamento de acordo com a função de fluxo, representadas pelas linhas cheias nos gráficos, denominadas índices de fluxo (ff) constantes, sendo a região de fluxo muito coesivo para $\mathrm{ff}<2$; fluxo coesivo para $2<\mathrm{ff}<4$; fluxo fácil para $4<\mathrm{ff}<10$ e fluxo livre para ff $>10$.

Figura 1 - Função de fluxo para as amostras secas e úmidas, respectivamente

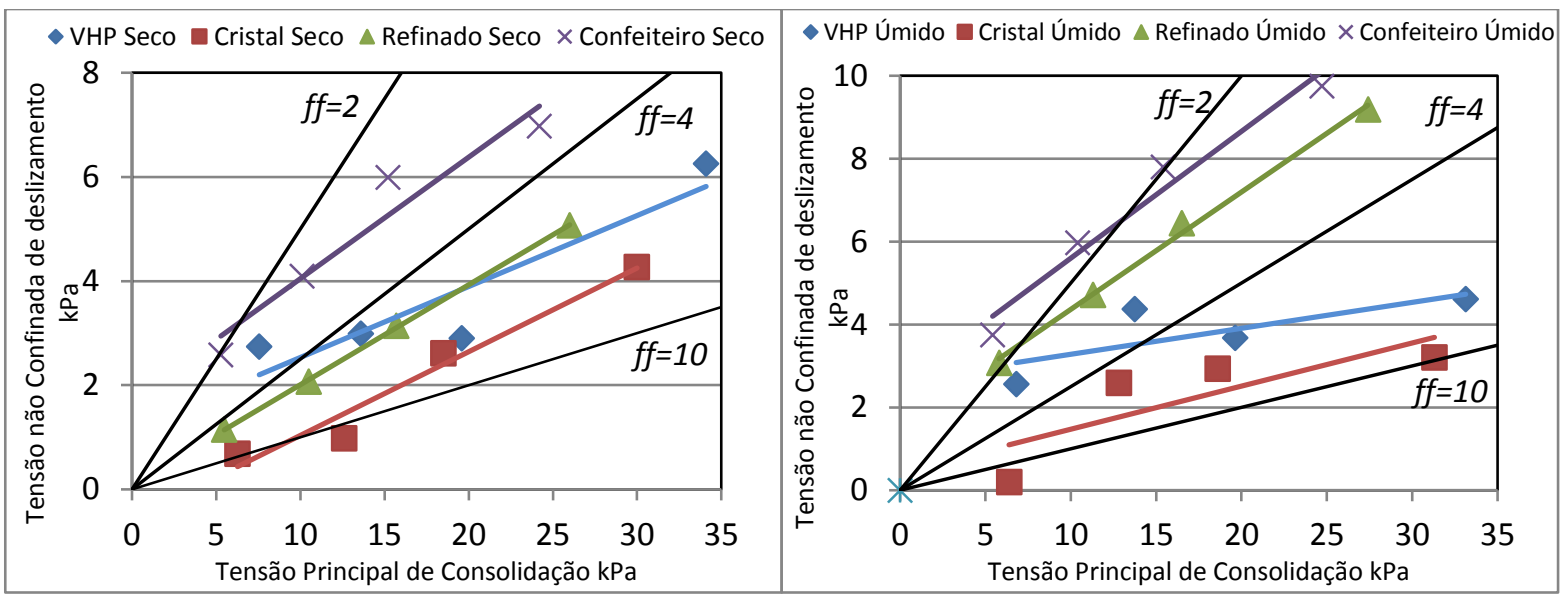

Energia básica de fluxo (BFE), Índice de estabilidade (SI) e fluxo variável (FRI): O teste de estabilidade consiste de 7 ciclos onde a lâmina ( $48 \mathrm{~mm}$ de comprimento) percorre $160 \mathrm{ml}$ de amostra com velocidade $100 \mathrm{~mm} / \mathrm{s}$ e a energia dispendida em cada ciclo monitorada. A variação desta energia ao longo dos 7 ciclos constitui o índice de estabilidade. Já a energia básica de fluxo (BFE) é considerada pela energia dispendida pela lâmina durante o $7^{\circ}$ teste. $\mathrm{O}$ teste de fluxo variável consiste de 4 ciclos onde a velocidade da lâmina é variável: 100, 70, 40 e $10 \mathrm{~mm} / \mathrm{s}$. Os índices de estabilidade (SI) e fluxo variável (FRI), assim como a energia básica de fluxo (BFE) obtida para cada tipo de açúcar nas diferentes condições são apresentados nas Tabela 3.

Comparando os valores de BFE das amostras úmidas e secas, as secas possuem os valores dos parâmetros maiores aos das amostras úmidas, para todos os tipos de açúcar, isto pode ser explicado pela diferença da configuração do leito nas amostras úmidas, a umidade aumenta as forças interparticulares entre as partículas formando os aglomerados, estes por sua vez se compactam, disponibilizando espaços vazios no interior leito, devido a morfologia irregular das partículas que não permite um arranjo linear, estes espaços vazios oferecem menor resistência a movimentação da lâmina, necessitando então de menor energia. 
Tabela 3 - Parâmetros de fluxo obtidos para amostras secas e úmidas

\begin{tabular}{|c|c|c|c|}
\hline Material & BFE, mJ & SI & FRI \\
\hline Açúcar Cristal Seco & $5325,4 \pm 1059$ & $1,246 \pm 0,124$ & $1,177 \pm 0,106$ \\
\hline Açúcar Refinado Seco & $2530,0 \pm 326$ & $1,021 \pm 0,063$ & $0,867 \pm 0,0397$ \\
\hline Açúcar Confeiteiro Seco & $1777,9 \pm 118$ & $1,025 \pm 0,039$ & $1,038 \pm 0,0389$ \\
\hline Açúcar VHP Seco & $2713,8 \pm 194$ & $1,008 \pm 0,049$ & $1,009 \pm 0,0115$ \\
\hline Açúcar Cristal Úmido & $5218,2 \pm 2346$ & $1,116 \pm 0,080$ & $0,825 \pm 0,418$ \\
\hline Açúcar Refinado Úmido & $1098,9 \pm 74,8$ & $0,923 \pm 0,077$ & $1,159 \pm 0,049$ \\
\hline Açúcar Confeiteiro Úmido & $1267,4 \pm 16,6$ & $1,043 \pm 0,051$ & $1,160 \pm 0,023$ \\
\hline Açúcar VHP Úmido & $1973,1 \pm 41,1$ & $0,962 \pm 0,070$ & $1,000 \pm 0,024$ \\
\hline
\end{tabular}

Índice de compressibilidade: A mudança na densidade do material em função da tensão normal aplicada foi medida e caracterizada como índice de compressibilidade. Cada tensão normal é aplicada durante um tempo definido para permitir que o leito alcance o equilíbrio. A distância percorrida pelo pistão é medida para cada tensão normal aplicada e a compressibilidade é calculada automaticamente como uma variação percentual no volume. Isto também pode ser representado como uma densidade absoluta ou relativa (Freeman, 2007). Os dados obtidos dessa análise para as amostras secas e úmidas, estão representadas na Figura 2.

Figura 2 - Índice de compressibilidade para as amostras secas e úmidas, respectivamente.
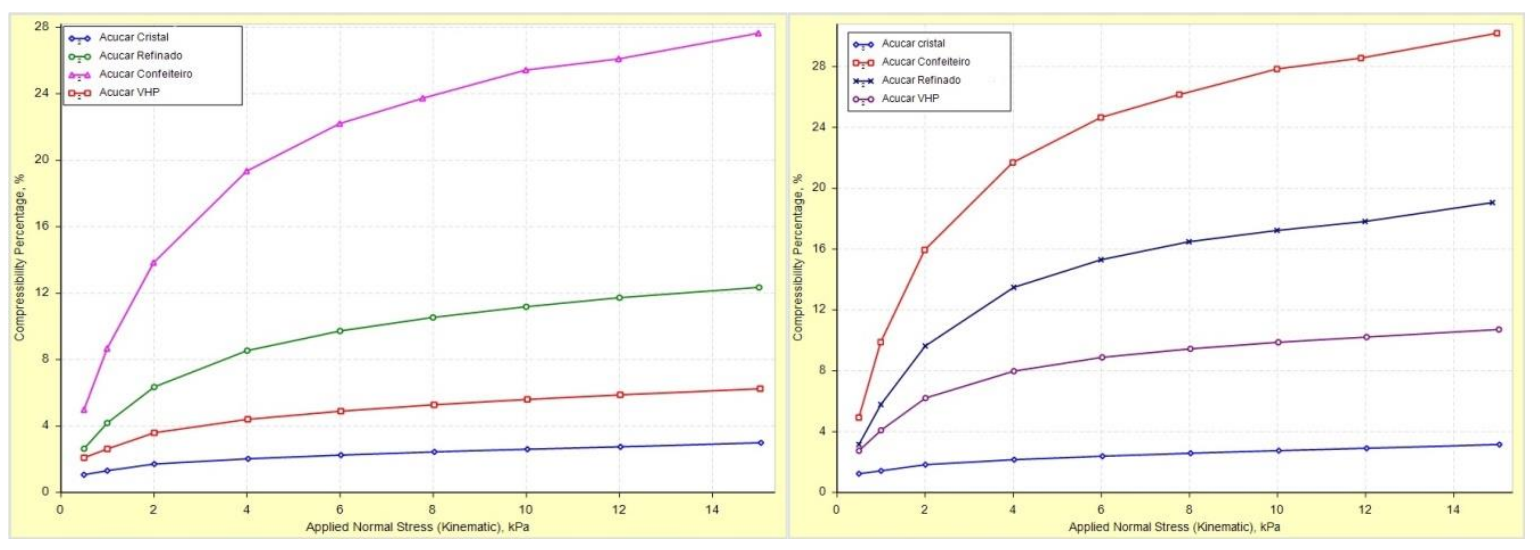

Para ambas as análises secas e úmidas, o Açúcar Confeiteiro apresentou a melhor compactação, isto pode ser explicado através da morfologia do material, que por possuir dimensões menores, tem maior tendência de formar aglomerados, e maior facilidade de ocupar os espaços vazios presentes no leito, quando aplicada a força normal, e isto é intensificado quando a amostra está úmida pois a intensidade dos aglomerados é maior, obtendo um maior volume de vazios que são mais facilmente ocupados.

Os Açúcares VHP e Cristal, na análise seca, obtiveram o resultado esperado, as curvas assemelham-se, e são muito próximas, pois se tratam de partículas de dimensões muito próximas. No entanto nas amostras úmidas, o Açúcar Cristal manteve o perfil da curva, portanto conclui-se que a compressibilidade desse material é pouco afetada pela umidade presente no leito. Já o Açúcar VHP aumenta a sua compressibilidade na amostra úmida. 
O açúcar Refinado foi o que obteve a maior diferença de porcentagem de compressibilidade, da amostra seca para a úmida, portanto conclui-se que este açúcar possui maior sensibilidade a umidade quando sob a influência de compactação, explicando então o fato de "empedramento" do material quando submetido às condições comerciais de empilhamento, armazenamento e exposição às variações ambientes (supermercados), o que ocorre também para o Açúcar Confeiteiro que se compacta com maior facilidade, mesmo em condições secas quanto úmidas.

\section{CONCLUSÕES}

Dentre os açucares analisados, o refinado e confeiteiro foram o que absorveram mais umidade e, consequentemente, apresentaram as piores classificações segundo índice de Hausner e menores valores de BFE e Função de Fluxo. Os baixos valores de BFE se devem a formação de aglomerados vazios que oferecem menos energia ao movimento da lâmina. Estes aglomerados, por sua vez, sofrem colapso quando submetidos a compressão, o que resultou nas maiores taxas de compressão destes mesmos açúcares.

Em relação aos açucares cristal e VHP, estes absorveram uma pequena quantidade de umidade, onde os resultados dos testes clássicos apresentaram praticamente os mesmos resultados para as amostras secas e úmidas. Entretanto, consideráveis diferenças foram observadas nos testes realizados com auxílio do reômetro de pó, mas que ainda necessitam de melhores interpretações

\section{REFERÊNCIAS}

DUFFY, S. P.; PURI, V. M. Flowability parameters and flow functions for confectionery sugar and detergent powder at two moisture contents. Appl. Eng. Agric., v. 12, n. 5, p. 601-606, 1996.

FITZPATRICK, J. J.; BARRINGER, S. A.; IQBAL, T. Flow property measurement of food powders and sensitivity of Jenike's hopper design methodology to the measured values. J. Food Eng., v. 61, n. 3, p. 399-405, 2004.

FREEMAN, R. Measuring the flow properties of consolidated, conditioned and aerated powders - A comparative study using a powder rheometer and a rotational shear cell. Powder Technol., v. 174, n. 1-2, p. 25-33, 2007.

JULIANO, P.; BARBOSA-CÁNOVAS, G. V. Food Powders Flowability Characterization: Theory, Methods, and Applications. Annu Rev Food Sci Technol. v. 1, n. 1, p. 211-239, 2010.

MACHADO, S. S.; Tecnologia da Fabricação do Açúcar. Univ. Federal de Santa Maria, 2012. PELEG, M. Flowability of food powders and methods for its evaluation-a review. J. Food Process Eng., v. 1:, p. 303-328., 1977.

SCICOLONE, J. V.; METZGER, M.; KOYNOV, S.; ANDERSON, K.; TAKHISTOV; P. GLASSER, B. J.; MUZZIO, F. J., Effect of liquid addition on the bulk and flow properties of fine and coarse glass beads. AIChE Journal. v. 62, n. 3. p. 648 - 658, 2015.

SANTOS, L. C. Obtenção das propriedades de fluxo de diferentes tipos de açúcar. Dissertação (Pós-Graduação em Engenharia Química) - Departamento de Engenharia Química, Universidade Federal de São Carlos, São Carlos. 114 f. 2017. 